\section{Una matriz \\ crítica. Jesús Díaz \\ y la vanguardia \\ cultural en Cuba.}

Irina Garbatzky

Recebido em:14 de abril de 2019

Aceito em: 16 de abril de 2019
Doctora en Humanidades y Artes (mención en Letras), por la Universidad Nacional de Rosario. Es Investigadora Adjunta del CONICET, en el Instituto de Estudios Críticos en Humanidades (IECH) y Jefa de Trabajos Prácticos en la cátedra de Literatura Iberoamericana I (UNR). Publicó como autora Los ochenta recienvivos. Poesía y performance en el Río de la Plata (2013) y como compiladora Expansiones. Literatura en el campo del arte (2013). Junto a Ana Porrúa, co-dirige la revista El jardín de los poetas. Revista de teoría y crítica de poesía latinoamericana.

Contato:sarbatzky@iechconicet. gob.ar

Argentina 
PALABRAS CLAVE: Jesús

Díaz; Vanguardia años 60;

Historia de los intelectuales

latinoamericanos; Literatura cubana
Resumen: La trayectoria de Jesús Díaz ha tendido a leerse de manera binaria: entre el adentro o afuera de la isla, el apoyo o la crítica a la revolución. Si bien estas oposiciones se presentan como radicales en el contexto histórico y en su propia vida, también podría decirse que en su obra se incluyen algunas continuidades de valores y procedimientos aprendidos durante la vanguardia cultural. En este artículo se señalan algunos, los que brindan un marco para acercarlo a la figura del intelectual crítico, ideada por Ángel Rama (1983) cuando pensó en el complejo lugar de tensión que habitaron los escritores durante la tormenta revolucionaria.

KEYWORDS: JesúsDíaz; 60s Avant-Gard; History of Latin American intellectuals; Cuban literature
Abstract: The trajectory of Jesús Díaz has tended to be read in a binary way: between inside or outside the island, support or criticism of the revolution. Although these oppositions are presented as radicals in the historical context and in their own lives, it could also be said that in their work some continuities of values and procedures learned during the cultural vansuard are included. In this article some are pointed out, those that provide a framework to bring it closer to the figure of the critical intellectual, devised by Ángel Rama (1983) when he thought about the complex place of tension that the writers inhabited during the revolutionary storm. 
En La vanguardia peregrina Rafael Rojas circunscribe, con la partida hacia 1961 de Guillermo Cabrera Infante y Carlos Franqui, integrantes de Lunes de Revolución, y con la emigración de Severo Sarduy, Julieta Campos o José Kozer, todos escritores con fuertes poéticas experimentales, el perfil de un grupo de intelectuales cubanos en el exilio asociado a la Nueva Izquierda; un socialismo libertario de tradición marxista, que ponía en cuestión la herencia soviética, al tiempo que tomaba las exploraciones del arte de los medios de comunicación, el estructuralismo, la vanguardia textualista, los incipientes movimientos de género. Desde afuera de la isla, explica Rojas, estos escritores continuarían afirmando y desarrollando tensiones vanguardistas en la historia literaria cubana, a través de producciones que ocuparon un lugar intersticial, innovador de las formas.

Ahora bien, desde adentro de la isla (y durante la misma década), la serie elaborada por Rojas permitiría iluminar la figura de Jesús Díaz: promotor de la vanguardia cultural de la Revolución, cronista singular de sus combates en los cuentos de Los años duros (1996), fundador y coordinador de $E l$ Caimán Barbudo (el suplemento cultural del periódico Juventud Rebelde), coordinador de la revista Pensamiento crítico, documentalista y guionista del ICAIC hasta su salida de Cuba en 1994 y gestor, desde Madrid, de la revista Encuentro de la literatura y la cultura cubana.

La trayectoria de Díaz interviene, entre la isla y el exilio, en núcleos fuertes de la historia de los intelectuales cubanos durante la segunda mitad del siglo XX. Como lúcidamente advirtieron Lilliam Oliva Collman (1999) e Yvon Grenier (2017), la ficción y el cine de Díaz no cesaron de 
explorar y evidenciar tanto los límites expresivos de la Revolución, como las propias posibilidades de instalación en el centro de sus debates. Lejos de mantener una constante marginalidad, opina Grenier, y a pesar de los sucesivos cuestionamientos y censuras a su producción, Díaz siempre consiguió colocar su trabajo en el cruce de las discusiones más acuciantes de su época. Su estrategia fue ocupar el espacio disponible y buscar el reconocimiento por el liderazgo cultural y político.

"La historia de la cultura cubana en la Revolución no puede escribirse sin el compromiso y la obra múltiple y abarcadora de Jesús Díaz. Lo curioso es que sin ella tampoco es posible escribir la historia del exilio cubano", sintetizó Iván de la Nuez (2002). La frase, también citada por Grenier, me interesa porque permite abrir los binarismos con los que ha sido leída su trayectoria: entre el adentro o afuera de la isla, el apoyo o la crítica al régimen. Si bien estas oposiciones no dejan de presentarse como radicales en el contexto histórico y en su propia vida, $-\mathrm{y}$, en este sentido, la crítica que así lo ha señalado no deja de acertar cuando expone las vicisitudes de esos pasajes-, ${ }^{1}$ también podría decirse que en su obra se presentan algunas continuidades, insistencias o retornos de valores, formas y procedimientos aprendidos durante los años de la vanguardia cultural. ${ }^{2}$

1 Díaz fue de la ilusión a la decepción, comenta Gustavo Guerrero (2002), o su historia puede leerse como la del intelectual redimido, según Rojas (2006).

2 En el apartado siguiente enumero las complejidades que la noción de vanguardia convoca en Cuba en la segunda mitad del siglo. Resulta necesario advertir que lo que aquí se señala como "vanguardia cultural" resulta un nuevo vanguardismo, distinto de la primera vanguardia de las décadas de 1920 y 1930, nucleada alrededor de una serie de revistas, fundamentalmente 
En este artículo quisiera ocuparme de señalar algunas. Fundamentalmente voy a subrayar aquellas que brindan un marco para acercarlo a la figura del intelectual crítico, ideada por Ángel Rama (1983) cuando pensó, llamando al debate, ese complejo lugar de tensión que habitaron los escritores durante la tormenta revolucionaria. Por otra parte, los formatos que Díaz exploró, particularmente los ligados con la tendencia documentalista y testimonial, no fueron abandonados por el autor, ni previamente ni con posterioridad a su salida de Cuba. Esto permitiría sugerir, antes que una interpretación sustentada en un "antes y después", una lectura que señalelas conexiones de un mismo espíritu crítico, vanguardista y cuestionador, desde los comienzos en La Habana hasta su exilio en Berlín y en Madrid. Acaso ello permitiría, además, de manera general, pensar más ampliamente los alcances de sus creaciones y de su trabajo como gestor cultural en la edición de publicaciones medulares. $Y$ de forma específica, dar sentido a los argumentos que afirmaba Rama, al sostener el hecho de que una mirada crítica no se oponía a una mirada revolucionaria y transformadora de la realidad.

Aunquela ruptura que Díaz impulsó, junto a otros artistas y escritores en los sesenta, se volvería contraria a la necesidad de un relato sin fisuras por parte del régimen, ciertamente su mirada sobre la realidad y la confianza en el arte como medio eficaz para su transmisión persistirían hasta la última

la revista de avance. Para estudiar los procesos y las vueltas de la vanguardia histórica en Cuba resulta indispensable el estudio de Celina Manzoni Un dilema cubano. Nacionalismo y vanguardia (2001). 
novela, Las cuatro fugas de Manuel (2002), donde recuperaría modos del distanciamiento formal y de la denuncia para mostrar, de manera compleja, la crisis de una idea unívoca de futuro, a la par de la emergencia de múltiples valencias y lecturas de lo porvenir que circulaban ya de cara al nuevo siglo.

\section{UNA MATRIZ CRÍTICA}

En 1966, Jesús Díaz recibe el premio “Casa de las Américas”, que consistió en la publicación de su primer libro, Los años duros. Los cuentos que lo integraban se ocupaban de narrar los momentos previos a la Revolución, la lucha contra la dictadura de Batista. Ángel Rama lo incorpora como uno de los casos clave de la escritura revolucionaria. ${ }^{3}$ Como Norberto Fuentes, -otro joven narrador que había retratado muy de cerca el vértigo de esos días, ya que había participado en la persecución a los bandidos norteamericanos en la isla, y su crudeza había transgredido las normas

3 Rama realiza un primer acercamiento al problema en 1971, el número 49 de Cuadernos de marcha, como respuesta a la polémica generada en torno al "Caso Padilla" y el proceso de transformación cultural en la isla (Blixen-Barros Lemez, 1986, 41-42). El artículo luego fue ampliado para el volumen Literatura y clase social, de 1983. Por esos años, cuando prepara el ensayo "Medio siglo de narrativa latinoamericana (1922-1972)", publicado en 1973 como prólogo del volumen Latinomericana: 75 narratori, editado por Franco Mogni, y luego, en 1982, como capítulo de La novela en América Latina. Panoramas 1920-1980, Rama expone de manera sintética el giro que se había dado en la literatura cubana a partir de la revolución hacia "una narrativa documental, realista, dura y a veces programática" $(2008,224)$. En esa narrativa ubica los cuentos de Jesús Díaz y de Antonio Benítez, junto a Norberto Fuentes. Se trata, según lo propone en su análisis sobre Fuentes, de un trabajo sobre el realismo muy diferente al que seguían los escritores que se plegaban "a ciertas convenciones en el manejo del tema revolucionario como las que ilustra la narrativa de Manuel Cofiño” (1983, 254). 
heroicas del relato oficial de la revolución-, Los años duros también exponía el proceso revolucionariosin recurrir a un imaginario mitificante. ${ }^{4}$

El conflicto se trazaba respecto del valor rupturista en la escritura. Para estos escritores el sumergimiento en la realidad revolucionaria, la "caracterización justa" de su violencia y su radicalidad, se colocaba por sobre cualquier modelo escriturario previo. Es este recurso el ponderado por Rama para pensar la transmisión de un acontecimiento social absolutamente transformador de la historia. Una escritura que desbordase todo molde literario previsto, incluso los elementos de la heroicidad y de la gloria, del bien y de mal, de las causas y las consecuencias. Rama encuentra el valor vanguardista de los escritores en su capacidad de poner en relación las nociones de experiencia, vivencia y narración de la realidad social:

La virtud más ardiente de esta concepción que otorga frescura y verdad a la composición artística, que hace su novedad revolucionaria con respecto a los discursos establecidos, radica en que se trata de un hallazgo que se cumple en la producción artística, paralelamente al proceso que lleva adelante una conciencia para construirla. Es muy difícil que tal hallazgo

4 Dice Rafael Rojas: "A pesar de haber sido escritos, resueltamente, como pequeños relatos dentro de la gran narrativa revolucionaria, Los años duros se aproxima al otro bando con un realismo inusual, en el que no faltan testimonios de la humanidad e, incluso, de la coherencia moral del adversario. Tres personajes de aquel libro serían buenos ejemplos de una caracterización justa del rival: Boby, el joven revolucionario que se exilia en los últimos años de la dictadura de Batista y que regresa a La Habana convencido de que la Revolución no debe forzar una ruptura con Estados Unidos, el Diosito, un revolucionario católico que debe enfrentarse al rechazo ideológico de sus compañeros de armas y, finalmente, el Niño, un 'bandido' valiente, que comparte los mismos atributos de 'hombría' e intransigencia de los milicianos que lo persiguen por los montes del Escambray" (Rojas 2006, 311, el subrayado es mío). 
pueda ser sustituido por un discurso previamente ordenado, sobre todo cuando éste, por mayores que sean las adecuaciones a que se lo someta, no deja de ser un plan preestablecido sobre la realidad con vistas a una acción y no la expresión directa y vivida en el plano de la producción estética de la construcción de la realidad de un determinado momento (1983, 255) (El subrayado es mío).

Rama proponía que el intelectual crítico debía permanecer dentro de la tensión que suponía apoyar los procesos políticos de transformación social y al mismo tiempo mantener la propia especificidad intelectual, fundamentalmente en términos de autonomía; mantener "la libertad crítica dentro de una sociedad socialista en construcción” (p.235). El caso de Fuentes resultaba ejemplar en este sentido, ya que al momento de ser señalado por Padilla en su famosa "autocrítica”, argumentó que defendía el ejercicio de su perfil cuestionador justamente por sentirse partícipe de la revolución y no por oponerse a ella. Para Rama, Fuentes recortaba un ideal de escritura, "un espíritu abierto, libre, inventivo", más cerca del periodismo que de la alta cultura, cuya participación en la lucha le permitía crear "a partir de una experiencia propia y profunda de la realidad, no a partir de una cartilla programática, simplificada para la divulgación masiva” (258).

La dicotomía entre la literatura revolucionaria y la literatura de propaganda fue objeto de un intenso debate en el que Díaz participó hacia 1966. En su respuesta a la Encuesta "Literatura revolucionaria" de la

5 Díaz inicia la polémica con la respuesta a la encuesta "Literatura revolucionaria" en la revista Bohemia 22 de julio de 1966. Jesús Orta Ruiz, cuyo seudónimo popular era Indio Naborí, le 
revista Bohemia, Díaz abogaba por una literatura de vanguardia en el marco de la revolución cubana, "en términos de vanguardia artística universal", cuestionando, como ejemplos de literatura de propaganda, las décimas de Jesús Orta Ruiz, conocido como el Indio Naborí. En sintonía con su tiempo, -me refiero a los debates acerca de la eficacia política de la forma que recorrieron las varias experiencias vanguardistas latinoamericanas de los años sesenta, acompañadas por las reflexiones sobre el pop y los medios de comunicación de masas-, ${ }^{6}$ Díaz introduce la discusión proponiendo un pensamiento sobre la obra de vanguardia en la isla y la resignificación que la misma debería producir en la cultura popular. La respuesta del Indio Naborí no se dejó esperar y apuntó justamente a esa órbita: la literatura revolucionaria sería aquella épica que surgiría del pueblo cubano; y el poeta futuro, el bardo homérico que pudiera cantarla. Así, en una segunda intervención, bastante más larga, titulada "Para una cultura militante", Díaz replica ratificando la problematización en torno al vínculo entre arte y cultura popular, trazando un camino que distingue la "serialización"

respondeen "Respuesta fraternal a Jesús Díaz", también en Bohemia el 5 de agosto de 1966. Díaz vuelve a replicar en "Para una cultura militante" publicada en Bohemia el 16 de septiembre del mismo año. Paralelamente, Díaz abre otra polémica, en el mismo año, con los escritores de su propia generación, más precisamente con los editores de El puente. Ese intercambio, que deriva en una discusión con Ana María Simo, se publica en La Gaceta de Cuba en los números 50, 51 y 52 del año 1966. Todos los artículos señalados se encuentran recopilados en el volumen Polémicas culturales de los 60, compilado por Reinier Pérez Hernández (2006). Las citas que realizo pertenecen a esa edición.

6 Para una exploración acerca de las teorías de los medios masivos de comunicación e información en el arte de la vanguardia estética y política en Argentina es recomendable el prólogo de Ana Longoni a la compilación de textos sobre Oscar Masotta La revolución en el arte (2004). 
capitalista del arte, de la transformación popular a la que propendería en el marco de la revolución: una integración de la tradición con lo nuevo, que permitirá "descubrir desde la óptica popular, con los más afinados elementos estéticos, nuevas realidades”. Reivindicará la originalidad, el valor artístico y la amplitud de la biblioteca cosmopolita. Si estos criterios resultan coherentes con los de otros episodios de las vanguardias históricas latinoamericanas y cubanas (el lenguaje nuevo, la articulación con la tradición, la equiparación universalista), ${ }^{7}$ aquí la renovación se sustenta en la asunción objetiva de elementos dela cultura popular y de los medios masivos de comunicación, -más precisamente el cine-, como dimensión crucial en la nueva realidad.

Un arte popular de vanguardia es posible, en Cuba lo tenemos: el Noticiero ICAIC. [...] Cuando, en la butaca de un cine de barrio: el Atlas, el Dora o el Maravillas, uno ve al pueblo, al pueblo real, no al que tienen en la mente los burócratas, gustar de una obra, identificarse con esa obra, reconocer el esfuerzo y la belleza y el respeto en esa obra (357-358). ${ }^{8}$

7 Para un estudio sobre estas dimensiones en la vanguardia cubana vuelvo a remitirme a Manzoni (2001).

8 Dice Lilliam Oliva Collman: "Se hace evidente, al examinar la posición de Díaz con respecto al tema de la confrontación generacional y a su definición de un escritor y literatura revolucionarios, que entabla y asume la dirección de la lucha en el campo ideológico" $(1999,6)$ y, en ese sentido, "Los años duros se propone corregir la imagen proyectada por PM al representar esta vez al pueblo en la tarea de construcción de una nueva sociedad militante. También se propone mostrar la formación de una vanguardia revolucionaria y una masa politizada por el movimiento insurreccional contra Batista, el entrenamiento de milicianos, el trabajo agrícola voluntario y la lucha contra el enemigo o los contrarrevolucionarios del Escambray" (8). 
El arte revolucionario no separaría la renovación de la forma artística de un trabajo sobre sus mediatizaciones, y ello acompañaría los procesos de transformación. En ese punto, a una sociedad nueva corresponde una forma nueva que profundice en términos de "traducción" de la experiencia revolucionaria desbordante, "desgarradora" y "alucinante", y el futuro "donde el hombre no es más simple, sino más complejo; no más ignorante, sino más culto; no más irracional, sino más crítico y más consciente" (Díaz, 2006, 356).

Ana Longoni (2006) nos advierte acerca de la polivalencia del vocablo "vanguardia" y del cuidado que debemos tener al utilizarlo; para conocer sus alcances siempre se vuelve necesario circunscribir el sentido histórico desde dondese lo enuncia: las zonas, los énfasis, las disputas por su significación. En este caso, la posición de Díaz gira en torno a los ejes que similarmente retomaría Rama: calidad, trabajo formal, apropiación de los medios de comunicación, militancia, originalidad, universalidad y transmisión de la experiencia transformadora del presente. Esta posición, en consecuencia, revela que no se trataría solamente de un liberalismo formal o de su oficialización, sino de "traducir la crisis del mundo que todavía estamos destruyendo".

El problema se replicaba en los debates en torno a los géneros literarios, como lo relata Claudia Gilman. La noción de "crítica", como concepto

9 "La obra surgirá desde la Revolución, que no será vista como el limbo perfecto e incoloro que no es, sino como el mundo alucinante, desgarrador, contradictorio y hermoso que con su sudor y su sangre el escritor -como un ciudadano revolucionario más - está construyendo" (Díaz, 2006, 330). 
moderno por antonomasia, que suponía la vuelta sobre sí del pensamiento, implicaba sostener la autonomía de la propia mirada y afirmar la negatividad como premisa. Para una mirada crítica ningún relato se halla completo y concluido, sino que la historia siempre es pasible de ser reorganizada por los ojos de un lector que se apropie, de manera emancipada, del uso de los signos. Durante los años de la época, la idea de crítica además se asoció a un traspaso del valor por la disrupción estética a una vanguardia centrada en una mirada en detalle sobre la realidad, un "nuevo realismo". El artista de vanguardia sería ahora menos el que invente una nueva lengua que aquel que logre dar cuenta de la realidad a partir de su participación en ella; el que pueda sustentar un "realismo de intención crítica, altamente consciente del artificio de la forma, cuyo modelo podía ser perfectamente Bertolt Brecht" (Gilman, 2013, 317).

Sin dudas la noción de vanguardia en la isla atraviesa una serie de complicadas revisiones a lo largo de los años, después de 1959. Gilman da cuenta de esa intrincada constelación. Guiándose a partir de la segmentación hecha en torno a 1968 como año clave de los sesenta como época, cuando, en otras cuestiones, se trama un viraje del intelectualismo hacia el antiintelectualismo, la autora traza distintos momentos en la valoración del problema. Uno de ellos es, como citaba, la relación entre vanguardia y realismo. Hasta 1968, la novela realista aparece como el género privilegiado para Latinoamérica en su transformación social. En la búsqueda de un arte nuevo, la noción de "realismo" se resemantiza, separándola de la carga normativa (que traía del realismo socialista) y reuniéndola con una 
tradición y el anhelo de una renovación. El realismo se presentará como "desbordante, sin fronteras, crítico, experimental formalmente cuidadoso, temáticamente sin restricciones y peculiarmente no basado en el mensaje" (Gilman, 2013, 317). El escritor latinoamericano de vanguardia será así el que pueda visibilizar lo invisibilizado del continente, acudiendo a los procedimientos técnicos del arte moderno. Pero, avanzando la década, Gilman observa otro momento, en el que el vocablo "vanguardia" se torna confuso o conflictivo, cuando comienza a ser leído como arte elitista, livianamente experimental o liberal, y, por lo tanto, en franca oposición con los procesos sociales resistentes a la dependencia del continente.

En el artículo que Díaz escribe con Juan Valdés-Paz, "Vanguardia, tradición y subdesarrollo", a comienzos de la década siguiente, es posible observar cómo el concepto de "vanguardia cultural" busca trazar una síntesis dialéctica de estas discusiones en marcha.

Al concepto general de vanguardia [...] habría de agregar, a partir de una obra válida en sí misma, el aporte consecuente a la formación y desarrollo de la conciencia nacional, el proceso de incorporación técnica del lenguaje, sobre la base de una conciencia crítica con una perspectiva politica general que informe el proceso, la lucha por un saneamiento y una reelaboración crítica de los elementos del folklore y de la tradición en general, y la oposición participante a los subproductos culturales elaborados por el imperialismo y sus gestores nacionales (1977, 70, subrayados en el original).

En la puja entre una noción de vanguardia asociada al liderazgo y la instrucción política y una actitud experimental o antidogmática, lo que 
se va abriendo paso, según Gilman, es "la tensión entre el intento de democratizar la cultura y el de revolucionarla" (337). Entrando en los setenta, y, claramente, con la incorporación del género testimonio en el premio literario de Casa de las Américas de 1970, la discusión respecto del arte nuevo y la participación en la vida revolucionaria se plasmará en la creación o validación de nuevos géneros artísticos y formatos de transmisión: los talleres literarios, los panfletos, la canción de protesta, el cine político y por supuesto, la novela testimonial.

En esa encrucijada, entre la democratización cultural y la revolución de la forma, se situará la obra de Díaz, acaso sin salida. Entre la vocación crítica y la pasión por lo real, Díaz se forma como un artista coherente con la ruptura, no sólo por el realismo despasivizante de su narrativa, sino además por la experiencia vivida con la creación y posterior desvinculación de El Caimán Barbudo y el cierre de Pensamiento Crítico, dos publicaciones revolucionarias, teóricas y muy pop, ${ }^{10}$ cuya radicalidad rebasó los límites permitidos del discurso oficial. ${ }^{11}$ Es decir, tanto en sus producciones

10 Argumentar esta cualidad pop en estas publicaciones sería asunto de otro trabajo, en donde se puedan poner en relación, especialmente en Pensamiento Crítico, los contenidos de la revista (al día con la agenda de la Nueva Izquierda) con la experimentalidad de su soporte gráfico que proponía un juego interesantísimo entre el medio y el mensaje, para retomar las categorías de McLuhan, apelando a discursos de la cultura pop que ingresaban en el discurso intelectual, como la historietas y la multiplicación desjerarquizada de imágenes culturales diversas.

11 La historia del paso de Díaz por El Caimán Barbudo y por Pensamiento Crítico es bastante más extensa y debería ser analizada separadamente. Ha sido recuperada por él mismo en un interesantísimo ensayo (2000), y también por Artaraz (2005) y Rojas (2006). El mismo año de publicación de Los años duros Díaz inauguró la coordinación de El Caimán Barbudo, el suplemento cultural del periódico Juventud Rebelde, de la Unión de Jóvenes Comunistas 


\section{materiales como en los circuitos y redes construidas como editor (en este sentido, el caso de la revista Encuentro resultará paradigmático, ya que desde Madrid reorganizó el campo intelectual de la diáspora, volviéndose foco de religación entre sus miembros).}

de Cuba. El magazine se presentaba como órgano periodístico de la vanguardia, "obra de jóvenes revolucionarios, comprometida con la Revolución, con su Partido, que es igual a estar comprometida con la verdad y con el arte", según decía en el editorial del primero número. "El caimán barbudo" era de hecho una manera de decir "Cuba revolucionaria", o "Cuba rebelde" (el caimán en reemplazo de la silueta de la isla y los barbudos como sinécdoque de los jóvenes revolucionarios). La coincidencia de un tiempo de esplendor, según sostiene Díaz, de la cultura y la política, les hacía pensar en la posibilidad de una confluencia: "la ilusión de que una cosa era consecuencia de la otra, de que una 'vanguardia política', como decíamos entonces, era conciliable con una 'vanguardia artística' experimental e incluso herética” (Díaz 2000, 65). Por esos años, también, entre 1967 y 1971, se vinculó con la revista Pensamiento crítico, una publicación editada por el Departamento de Filosofía de la Universidad de La Habana, de teoría, discusión y difusión del pensamiento marxista, que intentaba elaborar reflexiones sobre el socialismo desde una tradición nacional y del marxismo occidental y que además buscó retomar, traducir y publicar los textos de filosofía y sociología sobre las transformaciones contemporáneas que habían significado el Mayo francés, el estructuralismo, la lingüística, estudios sobre las dos Alemanias, el marxismo leninista. Se trataba de una vertiente reflexiva que puso a la publicación en el ojo de la tormenta para los revisores del marxismo ortodoxo, que desde la "Crisis de los misiles" durante los sesenta, habían puesto un pie firme en la isla. Los dos episodios fracasaron. En 1967, en El caimán barbudo, Díaz había publicado una nota de Heberto Padilla que reseñaba negativamente la novela Pasión de Urbino de Lisandro Otero, -por entonces viceministro de cultura-, y elogiaba Tres tristes tigres de Guillermo Cabrera Infante, exiliado durante esos años. La decisión de publicar una reseña y no otra, le valió el cargo y fue cesado de la revista; esa fue la gota que colmó el vaso, además de la corrosión provocada por una serie de publicaciones irónicas, sexuales, humorísticas. En cuanto a Pensamiento crítico, que se mantuvo en pie y de manera autónoma durante algunos ańos, fue clausurada en 1971, después de varias intervenciones y acusaciones de antisovietismo y diversionismo ideológico. Su final fue una dilapidación literal, con una motoniveladora que desmanteló la casa donde funcionaba el Departamento de Filosofía (Díaz 2000, 70). Los ejemplos de las expulsiones y las clausuras de las revistas permitirían pensar, paradójicamente, en el compromiso de Díaz de sostener el pensamiento crítico como valor revolucionario. 


\section{DOS EJEMPLOS}

Me gustaría traer dos momentos de su narrativa para pensar los avatares de esta pasión crítica, en los que cumple con aquella premisa de "traducir [formalmente] la crisis del mundo que aún estamos destruyendo". Si bien ambos muestran de manera pequeñísima una perspectiva que debería extenderse a otros momentos de su trabajo, fundamentalmente el cinematográfico, los elijo porque sus diferencias extremas exponen el momento inicial y el último de su obra, y porque ambos reproducen, cuestionándose entre sí, una pregunta en torno a la temporalidad revolucionaria.

La consistencia del tiempo, que dejaba de estar configurada por la tradición o el pasado para entablar una violenta ruptura con él, y por lo tanto convertirse en una materia tan intensa como volátil, aparece de manera muy visible en Los años duros. Los cuentos exponían, con una claridad extraordinaria, la marca del acontecimiento revolucionario como la de un tiempo en blanco, que desmoronaba absolutamente el pasado. "El polvo a la mitad", por dar un caso, condensaba en dos páginas y una sola imagen el sentido absoluto de ese corte.

\footnotetext{
-Mire -señaló una iglesia estremecida- ahí bautizaron a Batista, no queda nada, ni yo -dijo.

Se esfumó entre la nube, luego ésta se movió por primera vez arremolinándose alrededor de la iglesia hasta taparla. Arranqué sin esperar a ver más.

-Qué tipo raro -dije a mi mujer.
} 
- ¿Cuál tipo? -me preguntó.

-El que se quedó en aquel...

Pero no había pueblo. Sólo una nube fija, larga, pegada al camino.

(1967, 48-49)

El pueblo de Fulgencio Batista, Fray Benito, había desaparecido. Junto al dictador, era ahora un pueblo fantasma disuelto en la nada, como un vacío sin ruinas. La imagen resulta clave para pensar la revolución como dislocación; la nueva historia que comienza se lee en ese blanco.

El futuro vuelto presente es solidario de la noción de eficacia política del arte, que Alain Badiou sintetizara de manera tan brillante con la noción de la "pasión de lo real" para pensar el siglo. El tiempo empieza de nuevo y sólo existe un presente, en la brecha de dos pasiones: la que, junto a la idea de fin, agotamiento, decadencia, despuntaba un comienzo radical. Se trata de dos convicciones aunadas en una síntesis disyuntiva: "destruir lo viejo, crear lo nuevo". Según Badiou, un acontecimiento sólo puede tener lugar cuando consigue subvertir las condiciones dadas en el pensamiento de una época, haciendo emerger un elemento no comprendido todavía en la cuenta de una situación, un elemento invisible, sólo concebible en su futuridad. Los años duros permite el trabajo sobre esa doble valencia desde el epígrafe de El siglo de las luces que inicia la primera serie de relatos, justamente sobre el tiempo roto, no casualmente llamada: "Muy al principio". Dice el epígrafe: "¿Qué habrá en torno mío que esté ya definido, inscrito, presente y que aún yo no pueda entender? ¿Qué signo, qué mensaje, qué advertencia....” (Díaz 1967, 9). 
Qué hay en las proximidades de ese yo y cuál es su mensaje para lo que viene. El epígrafe capta la doble tendencia del ojo de la vanguardia, que al mismo tiempo en que busca desentrañar lo real en el presente, procura captar los signos que propician lo que vendrá. La tarea de dar forma a ese momento que se percibe como suspendido, extraído del curso común de la historia, convertido en época trascendente y extraordinaria, logra transmitir tanto la "pasión de lo real" como la nueva hora revolucionaria.

El segundo ejemplo pertenece a su último libro, la novela Las cuatro fugas de Manuel. Allí la imagen del futuro regresa, sólo que se trata ahora de un futuro que se multiplica en diversas direcciones. A diferencia de lo que ocurría en "El polvo a la mitad", el futuro ya no se presenta como un vacío afirmativo que organiza teleológicamente la historia, sino que, por un lado, forma parte de una experiencia inigualable y perdida (haber vivido en el futuro del mundo, como lo sintetiza Iván de la Nuez), y, por otro, se presenta como una enorme y angustiante interrogación. ${ }^{12}$

Durante los años sesenta y setenta Díaz tomó la orientación testimonial como estrategia de producción. Como vimos, y según afirma Collman,

12 Cito un párrafo de Iván de la Nuez que creo resume muy claramente la dimensión dislocada del tiempo que perciben los escritores de la generación posterior a la revolución. "Si algo saben estos escritores, es que no basta con pensar el futuro. Es necesario situarse en él. Y esto a pesar de que se enfrenten, en un acto de esta envergadura, a una paradoja fundamental: el Futuro, así con mayúscula, ya ha sido habitado por ellos. ¿No nacieron y crecieron escuchando que 'el futuro pertenece por entero al socialismo'? ¿No fueron ellos los elegidos incontaminados, hombres y mujeres que crecerían sin la sombra del capitalismo hasta un mundo sin dinero y sin clases? Ahora, recién despertados del sueño futurista, recién llegados de ese porvenir, se ven conminados a imaginar y vivir un mundo diferente al prometido. Como si se balancearan en una cuerda floja entre el futuro perdido y el futuro posible" (2001, 9-10). 
Los años duros aspiraba a ser la crónica de la lucha revolucionaria. Más tarde, entre otros ejemplos, deberíamos sumar la recopilación y montaje de entrevistas a cubanos exiliados en el libro De la patria y el exilio y el documental 55 hermanos, que realizó a partir de dicha investigación. En los ochenta, se publica su novela Las iniciales de la tierra, que, escrita diez años antes, se titulaba originalmente Biografía política, y hablaba sobre su propia vida como intelectual revolucionario en Cuba, de los límites y los conflictos de esa experiencia. A lo largo de su obra, Díaz reitera una apuesta formal tendiente a poner en riesgo la estabilidad de la ficción para volverla un artefacto de transmisión crítica de la realidad, con el fin de dar cuenta de un tiempo tumultuoso y en permanente cambio. ${ }^{13}$

Por ello es que a pesar de haber sido escrita durante los noventa y en un contexto absolutamente distinto al de sus inicios, no es extraño que Las cuatro fugas de Manuel retome vestigios de esas vías testimoniales, de la "pasión por lo real" como guía. Ello se revela cuando, al final del libro, el autor coloca un epílogo que invierte el signo de lo que acabamos de leer. Ese epílogo, escrito en una primera persona que se presenta por primera vez en el libro como tal, cuenta que Manuel Desdín, el protagonista, existió, se refugió en Berlín, en la casa de Jesús Díaz, quien residía en ella como becario del DAAD, y que la novela es el producto de un testimonio mediado, realizado a lo largo de varios ańos de entrevistas. Las

13 Sería asunto de un trabajo más extenso abordar todos los casos de dicha poética documental en Díaz; algunos análisis parciales pueden leerse en los mencionados trabajos de Collman (1999), Paranaguá (2002), Díaz (2008) y Vera León (1993). 
cuatro fugas de Manuel, de este modo, construye un montaje de voces, representa laescenificación, objetivizante y distanciada de la generación de los hijos de la Revolución, que en lugar de fabricar el nuevo presente debe encontrar qué hacer con su futuro. Casi a la manera del extrañamiento brechtiano, el "epílogo" enmarca la obra y la distancia, estableciendo un nuevo pacto de lectura que nos lleva a repensar el texto y su intervención. El procedimiento crítico persiste en ese dar cuenta de la realidad bajo una forma mediada, que construye una apariencia de ficción y luego la desactiva, mostrando su artificio. Si este proceso la vincula irremediablemente con el género testimonial, de impacto fuertísimo en Cuba durante los años que rodearon a la revolución, ${ }^{14}$ aquello que se narra ya no es la vida como caso paradigmático de un proyecto o de una colectividad, sino las vicisitudes de una vida, desprendida de todo destino cierto.

"Huelga decir que nos sentíamos solos, desconcertados y con mucho miedo al futuro" (243), dice al finalizar Las cuatro fugas.... Ambientada en el año de caída de la Unión Soviética, el futuro está en crisis: no hay estabilidad económica y la precariedad para el grupo de cubanos, en el

14 Mabel Moraña describe el lugar y la función que ocupa el testimonio desde la segunda mitad del siglo XX, muy especialmente como emergencia de un género que hace trastabillar los límites de la literatura en el marco de los virajes culturales que surgieron como efecto de la revolución cubana, entre otros episodios históricos. El testimonialismo, además, es "una forma transicional, [...] que adquiere sólo en el 'yo represento' su legitimación. Detrás de cada voz testimonial hay un 'caso', una situación social paradigmática, quizá no en los particulares de la anécdota, pero sí en cuanto a la representación de las condiciones materiales de las que esa voz surge. Para que el testimonio tenga el valor de tal es imprescindible que exista esa onda expansiva que va desde la individualidad hacia la colectividad, desde la afirmación de identidad al reconocimiento de la Otredad, de la injusticia a la denuncia, de la vivencia al discurso" (1997, 146). 
cual el autor se incluye, se enuncia como muestra de la fragilidad global. ${ }^{15}$ El futuro del nuevo siglo es el miedo al futuro, una obsesión. Futuros del pasado, futuros perdidos o ganados, futuros del deseo individual, futuros de lo común, futuros de la ciencia.

No existe un futuro promisorio, sino una multiplicación de futuros posibles o de ninguno. Para el protagonista, estudiante del Instituto de las Bajas Temperaturas de Járkov, después de la penalización con la vuelta a Cuba y el abandono de sus estudios, el futuro comocarrera científica en la URSS se desmorona. Su caída aparece anunciada de diversas formas por los personajes que lo rodean. La novia que lo había abandonado, porque "no soportaba Járkov, ciudad feísima, no soportaba a los comunistas, ni a los nacionalistas, ni a aquella vida de mierda sin futuro donde todo era política y política y política" (Díaz, 2002, 36). Natalia, la amiga chilena hija de un desaparecido en la dictadura de Pinochet, quien le dice que huya a Occidente, porque el ideal del comunismo era un "futuro [que] estaba lejos, [...] cada vez más lejos, y él tenía que salvarse ahora, porque después de todo no era un político sino un científico, un ingenuo que no sabía vivir en aquel mundo de fieras" (p.44). Su maestro, Derkáchev,que le aconseja fugarse: "Váyase a Occidente', [...]. 'Aunque debo advertirle que no veo nada bueno en el futuro, Manuel, nada. Los comunistas perderemos y a cambio no ganará nadie'” (50, los subrayados son míos).

15 Una lectura de Las cuatro fugas de Manuel en términos de redefinición de la literatura cubana frente a la transformación de las fronteras globales y como redireccionamiento de la novela exotista es trabajada por Idalia Morejón Arnaiz (2008). 
Meses después de estar viviendo en Storkwinkel, en un dorado atardecer berlinés que se transformó insensiblemente en noche mientras él hablaba, Manuel contó por primera vez en mi presencia la historia narrada en este libro y desde entonces supe que había contraído la obligación de escribirla. A lo largo de los ańos le pedí otras veces que me la repitiera hasta que terminó por convertírseme en una obsesión y empecé a contarla yo mismo. [...] Puedo decir que narra hechos reales desde la perspectiva de su protagonista, al menos hasta donde mi imaginación y mis palabras hayan sido capaces de apresarlos (244).

El afecto con el cual esa primera persona asume, después del final de la ficción que hemos leído, la responsabilidad de narrar esa historia, mostrando, además, su condición "verídica”, nos permite imaginar en ella una proyección, que la desestabilizaría de sus límites ficcionales o estrictamente literarios. Como si, en definitiva, Las cuatro fugas de Manuel se articulara a través de una paradoja: a medida que se resquebraja, hacia fin de siglo, la idea de un futuro unívoco, -el que sostenía, en el presente revolucionario, la ruptura radical del tiempo-, se afirmaen la escritura el convencimiento del poder delarte como medio para transmitir y observar críticamente experiencias únicas, asociadas cona contecimientos clave de la historia política. ${ }^{16} \mathrm{Si}$ la obra de Díaz ha sido señalada como un excurso a través de los años de la ilusión a la desilusión, sería interesante observar

16 De hecho, también en ese final Díaz cuenta que Manuel no pudo dedicarse finalmente a la Física, sino a la Informática, participando en la elaboración de un "software de alta tecnología para la publicación de un diario digital cuya aparición modificó radicalmente su propia vida, la de Pablo y también la mía" (245). Acaso ese diario haya sido la propia revista Encuentro de la cultura cubana. 
que este pasaje no menoscaba la persistencia de un valor característico de sus años "vanguardistas": la confianza en su eficacia para transfigurar la realidad. Cuestión no menor, en un contexto de enorme crisis de los grandes relatos culturales. Hacia finales de siglo XX el futuro como heterotopía se fragmenta en múltiples posibilidades colectivas, afectivas, individuales, científicas, políticas. Aunque ello supusiera volver de ese futuro pasado, acaso en la vía de salida continúen vigentes algunos valores, ligados a la afirmación de la realidad, de la historia de vida y de la memoria, en un momento en el cual, en palabras de Huyssen, la misma búsqueda de lo real y su deseo de temporalidad se había vuelto utópica $(2002,271)$. En ese contexto, la importancia de la mirada crítica se reduplica, ya que sólo ella es capaz de recortar, distanciar, denunciar y poner en discusión el orden del discurso.

Si en sus comienzos como narrador, la perspectiva de Díaz escrutaba la percepción temporal del presente revolucionario, plasmándolo en la imagen del polvo y el vacío fecundo, treinta años después, la pasión por lo real sigue en pie, por cuanto se vuelca hacia la construcción de una novela que linda los límites de lo ficcional, apelando a recursos de lo testimonial, y que nuevamente se vuelve sobre la percepción del tiempo como efecto de una crisis. Esta vez se trata del quiebre en la idea de un futuro unívoco y de su astillarse en futuridades en fuga. Su mirada desordenadora, capaz de reunir lo dispar y mostrar su conflicto, continuaría manteniendo una potencialidad impensada en una época distinta, una historia ahora percibida en sus límites o pérdidas. 


\section{CONCLUSIÓN}

En este breve artículo he intentado situar algunos elementos de la mirada crítica en la poética de Jesús Díaz, en tanto perspectiva formada como parte de la compleja vanguardia cultural de la revolución cubana. Una mirada que tiende a volcarse sobre lo real, fundamentalmente a la experiencia irreductible del acontecimiento revolucionario y sus derivas, y que, tomando para ello elementos del género testimonial, entiende que esa realidad debe en marcarse crudamente, exhibiendo la mediación del arte, para poder mostrar los dilemas e inquietudes de una generación.

Para comprobar la hipótesis de que estos elementos persisten a lo largo de su obra, más allá de su posición personal, sería deseable un abordaje más completo de varios otros momentos de su trabajo (imposible de ser realizado en los límites de esta presentación). Aquí sólo tomé dos brevísimos ejemplos del primero y el último de sus libros. No obstante, el desafío permitiría vislumbrar las características críticas de su trayectoria, que llevaron a Díaz, en cada momento de su producción, a hallarse alternativamente en los debates centrales de su presente así como a ser, sucesivamente, cesanteado, censurado y exiliado. De esta manera, su mirada nos acerca la dimensión de una encrucijada para los escritores de su época. Si la literatura de los inicios de la revolución condensaba la complejidad de un sentido crítico, de ruptura con lo instituido, a la par de un tono afirmativo hacia el nuevo tiempo, el caso de Díaz, como el de otros autores, artistas o cineastas, habría de convertirse, en adelante, en el de un extremo vanguardista: aquel que, en el afán de inventar la forma "justa" 
para transmitir la radical singularidad de ese acontecimiento, desoyó todas las convenciones previstas, incluso aquellas que se volverían coherentes o esperables en el horizonte revolucionario.

\section{RefERencias Biblográficas}

Artaraz, Kepa. "El ejercicio de pensar: the rise and fall of Pensamiento critico". Bulletin of Latin American Research, 24(3), 2005, p. 348-366.

Badiou, Alain. El siglo. Buenos Aires: Manantial, 2005.

Blixen, Carina-Barros Lemez, Álvaro. Cronología y bibliografía de Ángel Rama. Montevideo: Fundación Ángel Rama, 1986.

Collman, Lilliam Oliva. Jesús Díaz. El ejercicio de los límites de la expresión revolucionaria en Cuba. New York: Peter Lang, 1999.

De la Nuez, Iván. "El Hombre Nuevo ante el otro futuro", De La Nuez, I. (comp.): Almanaque. Cuba y el día después. Barcelona: Mondadori, 2001. 9-20.

. "El intelectual, el corazón y la piel". En: Revista Encuentro de la cultura cubana, n' 25, Verano de 2002, 39-41.

Díaz, Desirée. "Los otros. Exilio y emigración en el cine de la revolución”. Archivos de la Filmoteca, junio de 2008, no 59, 163-183.

Díaz, Jesús. "Literatura revolucionaria” y "Para una cultura militante”. En: PérezHernández, Reinier (comp.). Polémicas culturales de los 60. La Habana: Letras cubanas, 2006, 329-332 y 343-363. . Los años duros. Buenos Aires: Jorge Álvarez, 1967. - "Cuba el fin de una ilusión. La quiebra de El caimán barbudo y la clausura de Pensamiento crítico". En: Claves de la razón práctica, 104, 2000, 65-68. . Las cuatro fugas de Manuel. Madrid: Espasa Calpe, 2002. 
Díaz, Jesús y Juan Valdés-Paz. "Vanguardia, tradición y subdesarrollo". En: Barnet, Miguel- Benedetti, Mario - Carpentier, Alejo y otros. Literatura y arte nuevo en Cuba. Barcelona: Editorial Laia, 1977, 65-82.

Huyssen, Andreas. "Recuerdos de utopía", En busca del futuro perdido. Cultura y memoria en tiempos de la globalización. Buenos Aires: FCE, 2002, 247-271.

Gilman, Claudia. Entre la pluma y el fusil. Buenos Aires: Paidós, 2013.

Grenier, Yvonne. “Jesús Díaz, 1941-2002: The Unintentional Deviationist”. En: Cuban Studies, Volume 45, 2017, 115-131.

Guerrero, Gustavo. “Jesús Díaz: ilusión y desilusión”. En: Revista Encuentro de la cultura cubana, $\mathrm{n}^{\circ}$ 25, Madrid, Verano de 2002, 10-18.

Longoni, Ana. "Oscar Masotta. Vanguardia y revolución en los años sesenta”. En: Masotta, Oscar. La revolución en el arte. Pop art, happenings y arte de los medios. Buenos Aires: Edhasa, 2004, 9-17.

. "La teoría de la vanguardia como corset." Pensamiento de los confines 18 , 2006, 61-68.

Manzoni, Celina. Un dilema cubano. Nacionalismo y vanguardia. La Habana: Casa de las Américas, 2001.

Moraña, Mabel. "Documentalismo y ficción: Testimonio y narrativa testimonial hispanoamericana en el siglo XX", Políticas de la escritura en América Latina. De la colonia a la Modernidad, Caracas: Ediciones eXcultura, 1997, 113-150.

Morejón Arnaiz, Idalia. "Nuevo exotismo: escritores latinoamericanos en tránsito”. XI Congresso Internacional da ABRALIC, Tessituras, Interações, Convergências, USP - São Paulo. http://www.abralic.org.br/eventos/ cong2008/AnaisOnline/simposios/068.htm

Paranaguá, Paulo Antonio. "Diálogo y contemporaneidad en el cine de Jesús Díaz". Revista Encuentro de la cultura cubana, n 25, Madrid, Verano de 2002, 28-33.

Rama, Ángel."Norberto Fuentes. El escritor en la tormenta revolucionaria". Literatura y clase social. México: Folios, 1983, 231-261. 
__ "Medio siglo de narrativa latinoamericana (1922-1972)". La novela en América Latina. Panoramas 1920-1980. Santiago de Chile: Ediciones Universidad Alberto Hurtado, 2008, 115-226.

Rojas, Rafael. Tumbas sin sosiego. Madrid: Anagrama, 2006.

. La vanguardia peregrina. El escritor cubano, la tradición y el exilio. México: Fondo de Cultura Económica, 2014.

Vera-León, Antonio. "Jesús Díaz: politics of self-narration in revolutionary Cuba”. Latin American literary review. Vol. 21, 41, 65-78. 